\title{
SISTEM E-PEDIATRIC UNTUK PENDIAGNOSAAN EFLORSEN DERMATIS MENGGUNAKAN TEOREMA BAYES
}

\author{
Puji Sari Ramadhan ${ }^{1)}$ dan Tugiono ${ }^{2)}$ \\ ${ }^{1,2}$ Sistem Informasi, STMIK TRIGUNA DHARMA \\ 1,2,Jl. AH Nasution No.73 B, Medan, 20142 \\ E-mail : pujisariramadhan@gmail.com ${ }^{1)}$, tugiono@gmail.com ${ }^{2)}$
}

\begin{abstract}
ABSTRAK
Pembahasan dalam penelitian ini mencakup penggunaan Sistem Pakar dalam menghasilkan pengetahuan dan informasi tentang Eflorsen Dermatis dengan menggunakan konsep penelusuran dengan teknik runut maju atau Forward Chaining sekaligus melakukan penerapan dan perhitungan dengan Teorema Bayes, nantinya konsep Teorema Bayes akan dimasukkan dan diterapkan ke dalam suatu sistem yang berbentuk aplikasi layanan diagnosa untuk dapat dimanfaatkan oleh masyarakat luas dalam mengidentifikasi sekaligus mendiagnosa Eflorsen Dermatis berdasarkan gejala-gejala yang dialami oleh masyarakat. Seperti diketahui bahwa penyakit Eflorsen Dermatis dapat menyerang siapa saja, hal ini didasari dengan ditemukannyasistem imunitas kulit yang tidak mampu menahan serang dari luar kulit sehingga dapat menyebabkan peradangan pada kulit. Hasil dari pembahasan dalam penelitian yang dilakukan ini nantinya akan membentuk suatu sistem cerdas dalam melakukan pendiagnosaan terhadap Eflorsen Dermatis. Dengan adanya aplikasi layanan ini dapat dijadikan sebagai solusi dari pencegahan dan penanganan dini terhadap penyakit Eflorsen Dermatis.
\end{abstract}

Kata Kunci: Kecerdasan Buatan, Sistem Pakar, Forward Chaining, Teorema Bayes, Eflorsen Dermatis

\section{PENDAHULUAN}

Setiap individu mahluk hidup dilengkapi dengan lapisan pelindung yaitu berupa kulit yang bertujuan untuk mencegah dan menangkal serangan luar yang mengganggu bagian dalam tubuh. Namun setiap manusia memiliki kemampuan perlindungan kulit yang berbedabeda, hal inilah yang menjadi faktor utama terjadinya penyakit atau alergi pada kulit yang disebabkan ketidakmampuan imunitas kulit dalam melindungi dan menghalangi bakteri, virus dan kuman yang menyerang tubuh. Salah satu penyakit kulit yang sering menyerang manusia terutama anak-anak adalah Eflorsen Dermatis. Penyakit ini diidentifikasi berasal dari serangan luar lapisan kulit yang menyebabkan perubahan struktruk dan kelaian pada kulit, jika penyakit ini tidak langsung ditangani maka akan terjadi peradangan kulit traumatik sampai rusaknya lapisan pada kulit.

Melihat besarnya kemungkinan penyakit ini menyebar dan menjangkit masyarakat, maka perlu dilakukan langkah antisipasi dan penanggulangan terhadap Eflorsen Dermatis, salah satunya adalah dengan membangun sebuah sistem yang memiliki kemampuan dalam mengakusisi sekaligus mendistribusikan pengetahuan ahli untuk dapat diolah menjadi informasi dalam menghasilkan kesimpulan pendiagnosaan atau prediksi. Dengan terbentuknya sistem ini diharapkan dapat membantu masyarakat dalam melakukan pendiagnosaan dan memberikan informasi terkait Eflorsen Dermatis sehingga dapat dilakukan penanganan dan pengobatan secara dini dalam upaya mengantisipasi penyebaran dan terjangkitnya Eflorsen Dermatis ditengah masyarakat.

Sistem diagnosis yang akan dibentuk akan menggunakan analisis Sistem Pakar yang dapat bekerja dalam melakukan pendiaagnosaan terhadap Eflorsen Dermatis dengan menggunakan penerapan konsep Teorema Bayes. Dengan penggunaan Teorema Bayes ini yang nantinya akan dimasukkan dan diterapkan kedalam sistem, diharapkan dapat menghasilkan nilai pendiagnosaan penyakit berdasarkan gejala-gejala yang dirasakan atau dialami oleh masyarakat serta mendapatkan informasi tentang hasil diagnosa dengan nilai persentase penyakit yang diderita.

Seperti yang telah diketahui bahwa penerapan Sistem Pakar telah banyak dipergunakan dalam mengatasi permasalahan-permasalahan yang berkaitan dengan prediksi atau pendeteksian hal yang memiliki nilai ketidakpasitian, tentunya ini sangat membantu dalam menghasilkan atau menyimpulkan suatu hal yang masih menjadi kemungkinan. Hal ini dapat diketahui dengan penggunaan Sistem Pakar yang telah dilakukan pada(Ramadhan, 2019) untuk pendeteksian Impetigo, selain itu dalam(Wulandari, Kadek and Made, 2018) digunakannya ES (Expert System) untuk melakukan prediksi terhadap penyebaran kasus demam berdarah, pada(Zuhaer and Alhabib, 2018) digunakannya ES dalam pengidentifikasian pola pengenalan wajah, disamping itu pula terdapat(Hanifah dkk., 2018) pendiagnosaan dengan teknik penelusuran maju pada penyakit Pterigium, kemudian pada(Nurajizah and Saputra, 2018) 
penggunaan ES dalam pendiagnosaan terhadap infeksi kulit kucing. Tidak hanya itu terdapat juga dalam(Putri and Saputra, 2018) bahwa digunakannya aplikasi Sistem Pakat untuk melakukan pendiagnosaan terhadap analisis awal kanker rahim.

Penggunaan Sistem Pakar lainnya dalam dunia kesehatan dapat terlihat dari penerapan Sistem Pakar pada(Ramadhan, 2018) untuk pendiagnosaan dermatitis imun, selain itu juga digunakan dalam(Ramadhan, 2018) untuk pendeteksian varicella simplex, kemudian disebutkan dalam(Ramadhan and Fatimah, 2018) digunakannya aplikasi Sistem Pakar untuk inflamasi dermatitis imun, selanjutnya pada(Tuslaela and Permadi, 2018) digunakannya untuk membantu menghasilkan diagnosa terhadap penyakit gigi dan mulut serta (Agha, Jarghon and Naser, 2017) untuk penyakit rematik poligmalia. Dalam (Hossain dkk., 2017) disebutkan bahwa Sistem Pakar telah teruji dalam melakukan diagnosa TBC dan (Joshi and Ashish, 2017) mampu melakukan analisa pertumbuhan kanker payudara dengan pendekatan kasus, disamping itu pula pengidentifikasian kasus tumor otak juga menggunakan Sistem Pakar(Yeni dkk., 2017) dan kasus pencernaan(Ashari, 2016) pada anak.

Tidak hanya digunakan dalam dunia kesehatan, Sistem Pakar telah banyak pula digunakan dalam aktifitas sehari-hari, seperti penggunaannya dalam(Minarn, Warman and Handayani, 2017) untuk identifikasi hama singkong, dan jambu biji(Verawaty , Mesran, Suginam, 2017), selain itu penggunaan Sistem Pakar dilakukan pada(Widjaja and Susilo, 2017) diagnosa kerusakan perangkat dan (Hadini, 2017) identifikasi ikan yang memiliki kandungan formalin serta (Mohamad Hadi, Misdram and A, 2016)digunakan dalam pendeteksian untuk penyakit pada unggas.

Dari hasil analisis penggunaan Sistem Pakar yang dikemukakan, dapat diharapkan untuk menghasilkan kesimpulan diagnosa yang tepat pula dalam kasus pendiagnosaan Eflorsen Dermatis menggunakan Teorema Bayes.

Sistem yang akan dibangun adalah Sistem EPediatric yang diformulasikan untuk dapat mengatasi permasalahn pendiagnosaan terhadap penyakit Eflorsen Dermatis dengan menggunakan penerapan dan perhitungan metode dari Teorema Bayes, sehingga mampu menghasilkan sebuah nilai kemungkinan dan persentase terhadap penyakit yang diderita berdasarkan gejala-gejala yang dirasakan oleh masyarakat. Sistem ini akan berjalan dengan mengikuti konsep Teorema Bayes sehingga dapat menyimpulkan prediksi hasil diagnosa yang tepat dan baik.

Dengan hadirnya layanan diagnosa terkandung dalam sistem ini, diharapkan akan berjalan dengan baik dan tepat sehingga dapat membantu masyarakat dalam tindakan atau langkah antisipasi untuk penyebaran Eflorsen Dermatis dan penanganan dini terhadap penyakit tersebut, selain itu dengan dilakukannya penelitian ini dapat menambah khazanah keilmuan dan pengembangan Sistem Pakar dalam melakukan pendiagnosaan terhadap Eflorsen Dermatis dan sebagai dasar pengujian dari metode Teorema Bayes. Seperti disebutkan dalam(Swastikawara, 2017) bahwa informasi layanan kesehatan dengan menggunakan sistem komputer dapat menjadi salah satu solusi yang baik.

\section{RUANG LINGKUP}

Dalam penelitian ini diperlukan ruang lingkup penelitian yang berfungsi untuk mengarahkan penelitian tetap fokus dan jelas, berikut paparan tentang ruang lingkup penelitian yang dilakukan :

1. Cakupan permasalaahan

Pada penelitian ini membahas tentang menciptakan sebuah sistem berbentuk layanan diagnosa yang digunakan untuk dapat mendeteksi penyakit Eflorsen Dermatis sehingga nantinya dapat membantu masyarakat dalam melakukan penanganan dini terhadap penyakit tersebut.

2. Batasan-batasan penelitian

Penelitian ini hanya akan membahas tentang gejalagejala yang bersifat klinis dan pengelolaan pengetahuan ditentukan oleh pakar.

3. Rencana hasil yang didapatkan

Terciptanya sebuah sistem yang mampu menghasilkan solusi diagnosa disertai dengan nilai kemungkinan atau persentase terhadap penyakit yang diderita.

\section{BAHAN DAN METODE}

Pada penelitian ini diperlukan landasan yang bersifat teoritis yang mendukung konsep dan analisa dari penelitian yang dilakukan serta dalam penelitian ini terdapat metode penelitian yang nantinya digunakan dalam menghasilkan solusi dan tercapainya tujuan penelitian.

\subsection{Kecerdasan Buatan}

AI merupakan konsep yang memiliki spesialisasi dalam penghimpunan pengetahuan yang dapat diterapkan kedalam sistem. Dalam (Ramadhan, 2019) dijelaskan bahwa kecerdasan buatan didefinisikan sebagai ilmu yang berkaitan dengan teknologi komputer yang didalamnya telah dimasukkan pengetahuan dan informasi.

\subsection{Sistem Pakar}

ES atau Expert System merupakan bagian dari kecerdasan buatan yang digunakan dalam menyelesaikan permasalahan yang berkaitan dengan ketidakpastian. Pada (Divya and Sreekumar, 2014) dikemukakan bahwa Sistem Pakar dirancangn untuk membantu manusia dalam menyelesaikan permasalahan dalam kehidupan sehari-hari dengan kualitas kepakaran.

\subsection{Forward Chaining}

Penelusuran maju atau sering dikenal dengan Forward Chaining merupakan jenis dari penelusuran 
yang dimiliki oleh Sistem Pakar. Pada (Yanto, Werdiningsih and Purwanti, 2017) digunakannya Forward Chaining untuk dapat mengetahui solusi atas fakta-fakta yang terjadi.

\subsection{Teorema Bayes}

Metode ini digunakan untuk masalah perhitungan dengan nilai kemungkinan yang ditentukan oleh pakar sehingga nantinya dapat menghasilkan persentase diagnosa terhadap fakta yang terjadi. Dalam(Ramadhan, 2018) disebutkan rumus persamaan dari Teorema Bayes adalah (1) sebagai berikut :

$$
P\left(H_{i} \mid E\right)=\frac{P\left(E \cap H_{i}\right)}{P(E)}
$$

Keterangan (1) :

$\mathrm{P}(\mathrm{H} \mid \mathrm{E})=$ Probabilitas Hipotesis $i$ terjadi jika Evidence terjadi

$\mathrm{P}(\mathrm{E} \cap \mathrm{H})=$ Probabilitas Evidence mengandung Hipotesis

$\mathrm{P}(\mathrm{E})=$ Total probabilitas Evidence

\subsection{Elforsen Dermatis}

Pada(Maharani, 2015) dijelaskan bahwa penyakit ini merupakan perubahan kondisi kulit yang diakibatkan traumatik atau serangan dari luar yang menyebabkan peradangan pada kulit. Eflorsen Dermatis sendiri terbagi menjadi dua yaitu Eflorsen Dermatis Primer dan Eflorsen Dermatis Sekunder.

\subsection{Metode Penelitian}

Penelitian ini menggunakan metode penelitian Reserch and Development yang memiliki fungsi untuk menghasilkan aplikasi berbentuk software, yang nantinya dipergunakan dalam melakukan pendiagnosaan Eflorsen Dermatis yang berdasarkan gejala-gejala yang dialami oleh orang yang terdeteksi Eflorsen Dermatis dengan Teorema Bayes. Selain itu penelitian ini memiliki kerangka kerja diantaranya Basis Pengetahuan, proses penelusuran Forward Chaining, dan akan dilakukan perhitungan menggunakan Teorema Bayes yang pada akhirnya akan menghasilkan nilai probabilitas atau persentase Eflorsen Dermatis yang kemungkinan terserang masyarakat.

\section{PEMBAHASAN}

Berdasarkan kerangka kerja yang telah disusun maka proses selanjutnya adalah mengerjakan dan mengikuti langkah-langkah atau tahapan yang telah dikemukakan.

\subsection{Basis Pengetahuan}

Dalam pembangunan Sistem Pakar yang digunakan dalam pendeteksian Eflorsen Dermatis berdasarkan gejala klinis yang dialami oleh masyarakat yang terdeteksi Eflorsen Dermatis, diperlukan pemindahan pengetahuan serta informasi kedalam sebuah aplikasi yang memuat basis pengetahuan. Berikut ini hasil pengumpulan basis pengetahuan padad tabel 1 terkait Eflorsen Dermatis dan gejela-gejala yang terjadi

Tabel 1. Basis Pengetahuan

\begin{tabular}{|c|c|l|c|c|}
\hline \multirow{2}{*}{ No } & \multirow{2}{*}{$\begin{array}{c}\text { Kode } \\
\text { Gejala }\end{array}$} & \multicolumn{2}{|c|}{ Nama Gejala } & \multicolumn{2}{|c|}{$\begin{array}{c}\text { Jenis Eflorsen } \\
\end{array}$} & & & $\checkmark$ & \\
\hline 1 & G001 & Bercak & $\checkmark$ & $\checkmark$ \\
\hline 2 & G002 & Urtica & $\checkmark$ & $\checkmark$ \\
\hline 3 & G003 & Papula & $\checkmark$ & \\
\hline 4 & G004 & Tuber & $\checkmark$ & \\
\hline 5 & G005 & Bulla & $\checkmark$ & \\
\hline 6 & G006 & Pustula & $\checkmark$ & \\
\hline 7 & G007 & Atrofi & $\checkmark$ & $\checkmark$ \\
\hline 8 & G008 & Guma & & $\checkmark$ \\
\hline 9 & G009 & Plak & & $\checkmark$ \\
\hline 10 & G010 & Abses & $\checkmark$ & $\checkmark$ \\
\hline 11 & G011 & Crusta & $\checkmark$ & $\checkmark$ \\
\hline 12 & G012 & Erosio & & $\checkmark$ \\
\hline 13 & G013 & Likenifikasi & & $\checkmark$ \\
\hline 14 & G014 & Ekskoriasi & & $\checkmark$ \\
\hline 15 & G015 & Keloid & & \\
\hline
\end{tabular}

Berdasarkan hasil pengumpulan data pengetahuan, maka dapat terbentuklah 2 buah aturan atau rule base sebagai berikut :

Rule 1: IF Bercak =Yes $A N D$ Urtica $=$ Yes $A N D$ Papula $=$ Yes $A N D$ Tuber $=$ Yes $A N D$ Bulla $=$ Yes $A N D$ Pustula $=$ Yes $A N D$ Atrofi=Yes $A N D$ Guma $=$ Yes $A N D$ Crusta $=$ Yes $A N D$ Erosio=Yes $T H E N$ Penyakit $=$ Eflorsen Dermatis Primer

Rule 2: IF Urtica $=$ Yes $A N D$ Papula $=$ Yes $A N D$ Guma $=$ Yes $A N D$ Plak $=$ Yes $A N D$ Abses $=$ Yes $A N D$ Crusta $=$ Yes $\quad A N D \quad$ Erosio $=$ Yes $\quad A N D$ Likenifikasi=Yes $A N D$ Ekskoriasi=Yes $A N D$ Keloid=Yes THEN Penyakit=Eflorsen Dermatis Sekunder

\subsection{Penelusuran Forward Chaining}

Pada tahapan ini akan dilakukan penelusuran terhadap fakta-fakta yang terjadi sehingga nantinya dapat diambil kesimpulan dari aturan yang telah dihasilkan. Sebagai contoh kasus terdapat pasien yang menderita gejala-gejala : Urtica (G002), Tuber (G003), Atrofi (G007).

Dari data kasus diatas dapat diketahui bahwa terdapat gejala yang masuk dalam kedua rule atau aturan, maka dapat ditelusuri sebagai berikut :

Rule 1: IF Urtica =Yes $A N D$ Tuber $=$ Yes $A N D$ Atrofi=Yes THEN Penyakit = Eflorsen Dermatis Primer

Rule 2: IF Urtica =Yes THEN Penyakit=Eflorsen Dermatis Sekunder

Berdasarkan hasil penelusuran aturan yang telah dilakukan maka kemungkinan pasien tersebut mengalami jenis penyakit Eflorsen Dermatis Primer dan Eflorsen Dermatis Sekunder, sehingga perlu melakukan perhitungan serta penerapan Teorema Bayes untuk dapat diketahui nilai kemungkinan atau peluang yang lebih besar dari kedua jenis penyakit tersebut. 


\subsection{Penerapan Teorema Bayes}

Setelah melakukan penelusuran, selanjutnya akan dibentuk nilai bobot kondisi dari setiap geala untuk dapat dilakukan penerapan Teorema Bayes, tahapan ini berfungsi untuk mencari solusi atas hasil diagnosa yang memiliki 2 kemungkinan sehingga akan diketahui nilai terbesar dari kedua jenis penyakit tersebut untuk dapat dijadikan nilai dan kesimpulan diagnosa. Berikut adalah nilai bobot yang terdapat pada tabel 2 :

Tabel 2. Nilai Bobot

\begin{tabular}{|c|c|l|c|c|}
\hline \multirow{2}{*}{ No } & \multirow{2}{*}{$\begin{array}{c}\text { Kode } \\
\text { Gejala }\end{array}$} & \multirow{2}{*}{ Nama Gejala } & \multicolumn{2}{|c|}{$\begin{array}{c}\text { Jenis Eflorsen } \\
\text { Dermatis }\end{array}$} \\
\cline { 4 - 5 } & & & Primer & Sekunder \\
\hline 1 & G001 & Bercak & 0.4 & \\
\hline 2 & G002 & Urtica & 0.4 & 0.2 \\
\hline 3 & G003 & Papula & 0.2 & 0.4 \\
\hline 4 & G004 & Tuber & 0.6 & \\
\hline 5 & G005 & Bulla & 0,3 & \\
\hline 6 & G006 & Pustula & 0.2 & \\
\hline 7 & G007 & Atrofi & 0.2 & \\
\hline 8 & G008 & Guma & 0.4 & 0.2 \\
\hline 9 & G009 & Plak & & 0.4 \\
\hline 10 & G010 & Abses & & 0.2 \\
\hline 11 & G011 & Crusta & 0.2 & 0.6 \\
\hline 12 & G012 & Erosio & 0.4 & 0.2 \\
\hline 13 & G013 & Likenifikasi & & 0.2 \\
\hline 14 & G014 & Ekskoriasi & & 0.6 \\
\hline 15 & G015 & Keloid & & 0.4 \\
\hline
\end{tabular}

Penyelesaian tahapan dari Teorema Bayes :

Langkah Ke-1 : Menghitung Total Nilai Bobot Gejala yang dialami :

1. Jenis Eflorsen Dermatis Primer:

$\begin{array}{ll}\text { Urtica } & =0.4 \\ \text { Tuber } & =0.6 \\ \text { Atrofi } & =0.6\end{array}$

Total Bobot $=0.4+0.6+0.6=1.6$

2. Jenis Eflorsen Dermatis Sekunder:

Urtica $=0.4$

Langkah Ke-2 : Menghitung Nilai Probabilitas Gejala terhadap Penyakit :

1. Jenis Eflorsen Dermatis Primer:

$(\mathrm{P} \mid \mathrm{H} 1)=0.4 / 1.6=0.25$

$(\mathrm{P} \mid \mathrm{H} 2)=0.6 / 1.6=0.375$

$(\mathrm{P} \mid \mathrm{H} 3)=0.6 / 1.6=0.375$

$\mathrm{P}(\mathrm{E} \mid \mathrm{Hk}) \quad \mathrm{x} \mathrm{P}(\mathrm{Hk})=(0.4 * 0.25)+(0.6 * 0.375)+$ $(0.6 * 0.375)=0.55$

2. Jenis Eflorsen Dermatis Sekunder:

$(\mathrm{P} \mid \mathrm{H} 1)=0.4 / 0.4=1$

$\mathrm{P}(\mathrm{E} \mid \mathrm{Hk}) \times \mathrm{P}(\mathrm{Hk})=0.4 * 1=0.4$

Langkah Ke-3 : Menghitung Nilai Bayes Akhir

1. Jenis Eflorsen Dermatis Primer:

$\mathrm{P}(\mathrm{H} 1 \mid \mathrm{E})=(0.4 \times 0.25) / 0.55=0.18$

$\mathrm{P}(\mathrm{H} 2 \mid \mathrm{E})=(0.6 \times 0.375) / 0.55=0.41$

$\mathrm{P}(\mathrm{H} 3 \mid \mathrm{E})=(0.6 \times 0.375) / 0.55=0.41$

$\sum$ Bayes $=(0.4 \times 0.18)+(0.6 \times 0.41)+(0.6 \times 0.41)=$

0.56 (Hasil Bayes)
2. Jenis Eflorsen Dermatis Sekunder:

$\mathrm{P}(\mathrm{H} 1 \mid \mathrm{E})=(0.4 * 1) / 1=0.4$

¿Bayes $=(0.4 * 0.4)=0.16($ Hasil Bayes $)$

Langkah Ke-3 : Mencari nilai probabilitas yang paling tinggi :

Jenis penyakit Eflorsen Dermatis Primer dengan nilai 0.56 sedangkan jenis penyakit Eflorsen Dermatis Sekunder memiliki nilai probabilitas 0.16. Maka dapat disimpulkan bahwa pasien tersebut menderita penyakit Eflorsen Dermatis Primer dengan nilai 0.56 atau dengan persentase $56 \%$.

\subsection{Implementasi Sistem}

Pada tahapan ini akan menunjukkan hasil dari sistem atau aplikasi diagnosa yang telah dibangun. Pada implementasi sistem ini akan ditampilkan beberapa halaman yang penting dalam memberikan layanan diagnosa kepada masyarakat, diantaranya : halaman utama, layanan data pasien, dan layanan data diagnosa.

1. Halaman Utama

Untuk mendapatkan layanan diagnosa pada sistem yang telah dirancang, maka terlebih dahulu pengguna mengakses halaman utama. Berikut tampilan halaman utama pada gambar 1 .

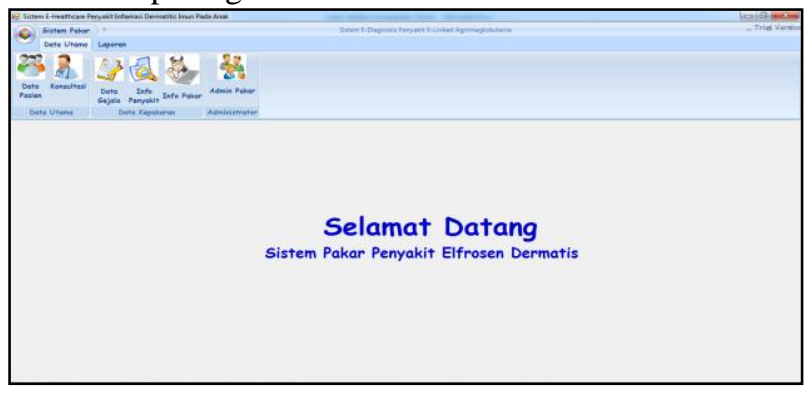

Gambar 1. Halaman Utama

2. Layanan Data Pasien

Layanan ini digunakan untuk mengelola data-data pribadi pasien sehingga nantinya dapat digunakan sebagai penyimpanan riwayat penyakit dari pasien tersebut. Pada layanan ini disediakan pengelolahan data seperti penyimpanan data, perubahan data, dan penghapusan data-data pasien. Berikut halaman layanan data pasien pada gambar 2 .

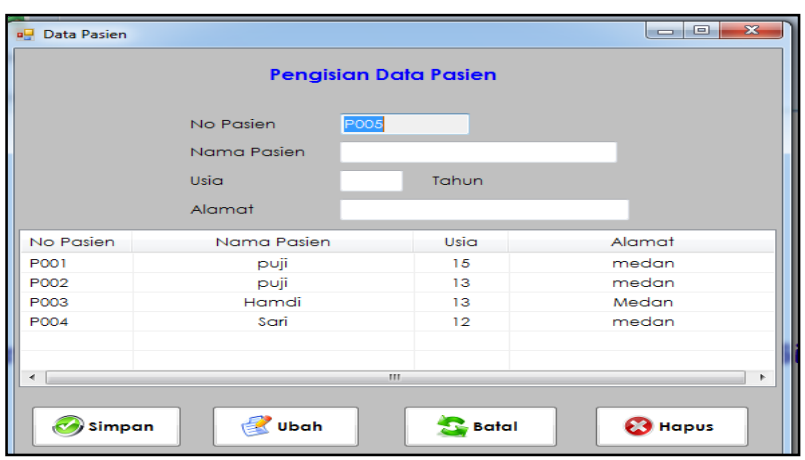

Gambar 2. Layanan Data Pasien 
3. Layanan Diagnosa

Layanan ini disediakan untuk layanan konsultasi yang dapat dipergunakan dalam melakukan pendeteksian terhadap Eflorsen Dermatis berdasarkan gejala-gejala klinis yang dialami. Pada layanan ini memiliki data-data berkaitan dengan konsultasi meliputi nama dengan kode pasien, gejala-gejala yang diderita dan hasil diagnosa disertai nilai probabilitas penyakit. Berikut ini halaman dari layanan diagnosa pada gambar 3 .

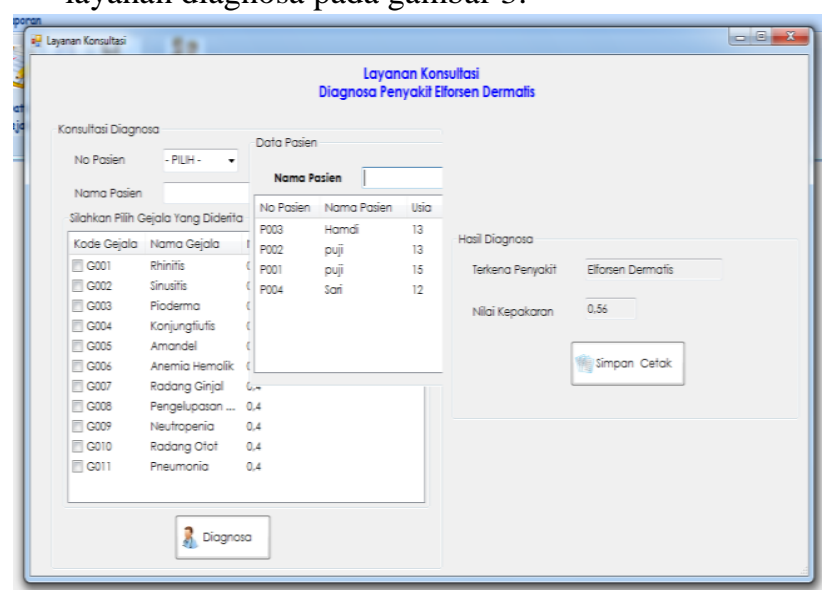

Gambar 3. Layanan Diagnosa

\section{KESIMPULAN}

Berdasarkan penelitian yang telah dilakukan maka dapat disimpulkan bahwa penerapan Teorema Bayes dalam melakukan pendeteksian Eflorsen Dermatis telah berhasil mengomtimalkan hasil diagnosa serta penerapan Sistem Pakar ke dalam bentuk layanan diagnosa dengan menanamkan proses atau tahapan yang meliputi pengumpulan basis pengetahuan, penelusuran runut maju, dan perhitungan dengan Teorema Bayes sehingga telah dapat digunakan oleh masyarakat luas untuk mengidentifikasi atau menanggulangi permasalahan tentang Eflorsen Dermatis .

\section{SARAN}

Diharapkan penelitian ini dapat berlanjut dengan penggunaan metode yang lainnya sehingga dapat terjadi perbandingan serta meningkatkan kualitas informasi dengan menggunakan gejala-gejala yang tidak hanya berdasarkan klinis tetapi juga dari sumber dalam tubuh yang dapat teridentifikasi.

\section{DAFTAR PUSTAKA}

Agha, M. El, Jarghon, A. and Naser, S. S. A. 2017. "Polymyalgia Rheumatic Expert System," (August).

Ashari .2016. "Penerapan Sistem Pakar Untuk Mendiagnosa Penyakit Pecernaan Dengan Pengobatan Alami," (November), pp. 1-9.

Divya, J. and Sreekumar, K. .2014. "A Survey on Expert System in Agriculture," International journal of computer science and information technologies, 5(6), pp. 7861-7864.

Hadini, F. M. 2017. "Detection System Milkfish Formalin Android-Based Method Based on Image Eye Using Naive Bayes Classifier," 9(1), pp. 2-5.

Hanifah, U. $d k k$. 2018. "DETEKSI PENYAKIT PTERIGIUM MENGGUNAKAN FORWARD CHAINING DAN ALGORITMA VIOLA JONES DETECTION OF PTERIGIUM DISEASE USING FORWARD CHAINING AND VIOLA," 5(3), pp. 6118-6125.

Hossain, M. S. $d k k$. 2017. "A Belief Rule Based Expert System to Assess Tuberculosis under Uncertainty," Journal of Medical Systems. Journal of Medical Systems, 41(3). doi: 10.1007/s10916-017-0685-8.

Joshi, A. and Ashish, M. 2017. "Analysis Of K-Nearest Neighbor Technique For Breast Cancer Disease Classification," International Journal of Recent Scientific Research, 8(8), pp. 1005-19008. doi: 10.24327/IJRSR.

Maharani, A. 2015. Penyakit Kulit. 1st ed. Edited by Mona. Yogyakarta: Pustaka Baru Press.

Minarn, Warman, I. and Handayani, W. 2017. "CaseBased Reasoning (Cbr) Pada Sistem Pakar Identifikasi Hama Dan Penyakit Tanaman Singkong Dalam Usaha Meningkatkan Produktivitas Tanaman Pangan," Jurnal TEKNOIF, 5(1), pp. 41-47. doi: 10.21063/JTIF.2017.V5.1.41-47.

Mohamad Hadi, Misdram, M. and A, R. F. 2016. "Perancangan Sistem Pakar Diagnosa Penyakit Ayam Dengan Metode Forward Chaining," JImp, 2(no bagian volume), pp. 111-139. doi: 10.1017/CBO9781107415324.004.

Nurajizah, S. and Saputra, M. 2018. "Sistem Pakar Berbasis Android Untuk Diagnosa Penyakit Kulit Kucing Dengan Metode Forward Chaining," Jurnal Pilar Nusa Mandiri, 14(1), pp. 7-14. Available at: http://ejournal.nusamandiri.ac.id/ejurnal/index.php/pi lar/article/view/750/pdf.

Putri, S. A. and Saputra, E. P. 2018. "Perancangan Aplikasi Sistem Pakar Diagnosa Awal Kanker Reproduksi Wanita Dengan Metode Certainty Factor," 2(3), pp. 63-68.

Ramadhan, P. S. 2018. "SISTEM PAKAR PENDIAGNOSAAN DERMATITIS IMUN MENGGUNAKAN TEOREMA BAYES," InfoTekJar(Jurnanl Nasional Informatika dan Teknologi Jaringan), 3(73), pp. 43-48.

Ramadhan, P. S. 2019. "PENERAPAN EUCLIDEAN PROBABILITY DALAM PENDETEKSIAN PENYAKIT IMPETIGO,” 4(1), pp. 11-16.

Ramadhan, P. S. and Fatimah .2018. "Sistem EHealthcare Untuk Mendiagnosa Penyakit Inflamasi Dermatitis Imun Anak Dengan Menggunakan Metode Certainty Factor," 1(1), pp. 251-256.

Swastikawara, S. 2017."Berkebutuhan Khusus ( Studi Pada Kelompok Deaf )," (2013), pp. 35-40.

Tuslaela and Permadi, D. 2018."Sistem Pakar Diagnosa Penyakit Gigi Dan Mulut Berbasis Web dengan 
Metode Forward Chaining," Jurnal PROSISKO, 5(1), pp. 17-26. Available at: http://ejurnal.lppmunsera.org/index.php/PROSISKO/article/ view/586/594.

Verawaty, Mesran, Suginam, A. K. 2017. "Jambu Biji Menggunakan Metode Bayes," 2(1), pp. 78-81.

Widjaja, A. and Susilo, A. B. 2017.“Expert System To Identify Damage Cisco As5300 Device With The Method Of Forward Chaining-Based Client-," 9, pp. 787-805.

Wulandari, Kadek and Made, S. 2018. "Prediction of Days in Hospital Dengue Fever Patients using KNearest Neighbor," 3(1), pp. 23-25.

Yanto, B. F., Werdiningsih, I. and Purwanti, E. 2017. "Aplikasi Sistem Pakar Diagnosa Penyakit Pada Anak Bawah Lima Tahun Menggunakan Metode Forward Chaining," Journal of Information Systems Engineering and Business Intelligence, 3(1), pp. 6167.
Yeni $d k k$. 2017. "Sistem Pakar Untuk Mendiagnosis Penyakit Tumor Otak Menggunakan Metode Certainty Factor (CF)," Jurnal INFOTEK, 2(1), pp. $0-4$. Available at: http://ejurnal.amikstiekomsu.ac.id/index.php/infotek/ article/view/98.

Zuhaer, M. and Alhabib, M. H. M. 2018. "Face Recognition System Based on Kernel Discriminant Analysis , K-Nearest Neighbor and Support Vector Machine," 5(3), pp. 335-338. 